\title{
PENGARUH INSENTIF JASA PELAYANAN, KEPEMIMPINAN DAN BEBAN KERJA TERHADAP SEMANGAT KERJA KARYAWAN DI RSUD SANJIWANI GIANYAR
}

\author{
Ni Wayan Wahyuliani ${ }^{1}$ \\ I Made Adi Suwandana ${ }^{2}$ \\ ${ }^{1,2}$ Fakultas Ekonomi Universitas Ngurah Rai, Bali, Indonesia \\ e-mail : yulikwwahyuliani@gmail.com
}

\begin{abstract}
ABSTRAK
Penelitian ini bertujuan untuk mengetahui pengaruh secara parsial dan simultan insentif jasa pelayanan, kepemimpinan dan beban kerja terhadap semangat kerja karyawan di RSUD Sanjiwani Gianyar. Penelitian ini dilakukan terhadap 51 responden yang merupakan seluruh seluruh karyawan paramedis keperawatan di Poliklinik RSUD Sanjiwani Gianyar dengan teknik analisis regresi linier berganda yang perhitunganya menggunakan bantuan SPSS for windows 23.0. Hasil penelitian menunjukkan insentif jasa pelayanan, kepemimpinan, dan beban kerja secara simultan berpengaruh positif dan signifikan terhadap semangat kerja karyawan di RSUD Sanjiwani Gianyar. Insentif jasa pelayanan berpengaruh positif dan signifikan terhadap semangat kerja karyawan di RSUD Sanjiwani Gianyar. Kepemimpinan berpengaruh positif dan signifikan terhadap semangat kerja karyawan di RSUD Sanjiwani Gianyar. Beban kerja berpengaruh negatif dan signifikan terhadap semangat kerja karyawan di RSUD Sanjiwani Gianyar.
\end{abstract}

Kata kunci : Insentif Jasa Pelayanan, Kepemimpinan, Beban Kerja, Semangat Kerja Karyawan

\section{ABSTRACT}

This study aims to determine the effect of partial and simultaneous service incentives, leadership, and workload effect on employee morale in Sanjiwani Hospital Gianyar. This study was conducted on 51 respondents who were all all nursing paramedics at the Sanjiwani Public Hospital in Gianyar with multiple linear regression analysis techniques which calculated using SPSS for Windows 23.0. The results showed that service incentives, leadership, and workload simultaneously had a positive and significant effect on employee morale in Sanjiwani Hospital Gianyar. Service incentive has a positive and significant effect on employee morale in Sanjiwani Hospital Gianyar. Leadership has a positive and significant effect on employee morale in Sanjiwani Hospital Gianyar. Workload has a negative and significant effect on employee morale in Sanjiwani Hospital Gianyar.

Keywords: Service Incentives, Leadership, Workload, Employee Spirit 


\section{PENDAHULUAN}

Sumber Daya Manusia (SDM) adalah suatu ilmu manajemen bagaimana mengatur hubungan dan peranan sumber daya (tenaga kerja) yang dimiliki oleh individu secara efisien dan efektif serta dapat digunakan secara maksimal sehingga tercapai tujuan bersama perusahaan (Nawawi dalam Gaol, 2014:44). Sumber daya manusia penting bagi kelancaran aktivitas yang ada di dalam perusahaan karena memang sebagian aktivitas di perusahaan memerlukan sumber daya manusia yang berkualitas agar tercapainya tujuan perusahaan dengan kinerja dan mempunyai semangat kerja yang baik (Robbins, 2009). Sumber daya manusia adalah kemampuan potensial yang dimiliki oleh manusia yang terdiri dari kemampuan berfikir, berkomunikasi, bertindak dan bermoral untuk melaksanakan suatu kegiatan baik bersifat teknis maupun manajerial (Sutrisno, 2014:3).

Kontribusi karyawan bagi organisasi sangat dominan, karena karyawan adalah penghasil kerja bagi organisasi. Hal ini beararti adalah setiap pekerjaan dalam organisasi selalu dilaksanakan oleh karyawan. Berhasil tidaknya suatu organisasi ditentukan oleh unsur manusia yang melakukan pekerjaan sehingga karyawan perlu diperlakukan dengan baik agar karyawan tetap bersemangat dalam bekerja.

Menurut Hasibuan (2016:101), semangat kerja adalah keinginan dan kesungguhan seseorang yang pekerjaan dengan baik serta disiplin untuk mencapai prestasi kerja maksimal. Semangat kerja akan merangsang seseorang untuk berkarya dan berkreatifitas dalam pekerjaannya (Hasibuan, 2014:76). Semangat kerja adalah perasaan seorang individu terhadap pekerjaan dan organisasinya (Syahropi, 2016). Jika semangat kerja rendah, kemungkinan partisipasi hanya akan terbatas pada apa yang diperintahkan. Widnyono (2013) mengemukakan semangat kerja dapat dipengaruhi oleh pemberian insentif dari perusahaan, pemberian insentif yang rendah dapat menurunkan semangat kerja karyawan.

Hasibuan (2013:118) menyatakan pengertian insentif adalah tambahan balas jasa yang diberikan kepada karyawan tertentu yang prestasinya diatas prestasi standar. Upah insetif ini merupakan alat yang dipergunakan pendukung prinsip adil dalam pemberian kompensasi. Insentif sebagai sarana motivasi yang mendorong para pegawai untuk bekerja dengan kemampuan yang optimal, yang dimaksudkan sebagai pendapatan ekstra di luar gaji atau upah yang telah ditentukan.

Kepemimpinan juga dapat mempengaruhi terhadap semangat kerja karyawan. Dalam suatu instansi, kepemimpinan merupakan suatu faktor yang menentukan tercapai atau tidaknya tujuan suatu instansi, dengan kepemimpinan yang baik, proses manajeman akan berjalan lancar dan pegawai bergairah melaksanakan tugastugasnya. Gairah kerja, produktivitas kerja, dan proses manajeman suatu instansi akan baik, jika tipe, cara, atau gaya kepemimpinan yang di terapkan pemimpinnya baik. Menurut Rivai (2012:53) kepemimpinan adalah kemampuan seseorang pemimpin untuk mempengaruhi orang lain dengan cara memancing tumbuhnya perasaan yang positif dalam diri orang-orang yang 
dipimpinnya untuk mencapai tujuan yang diinginkan.

Selain itu, yang tidak kalah penting yang dapat mempengaruhi semangat kerja karyawan adalah beban kerja yang harus dilaksanakan oleh karyawan. Dalam suatu perusahaan beban kerja merupakan salah satu aspek yang harus di perhatikan, karena beban kerja salah satu yang dapat meningkatkan semangat karyawan.

Menurut Komaruddin dalam Kurnia (2010) analisa beban kerja adalah proses untuk menetapkan jumlah jam kerja orang yang digunakan atau dibutuhkan untuk merampungkan suatu pekerjaan dalam waktu tertentu, atau dengan kata lain analisis beban kerja bertujuan untuk menentukan berapa jumlah personalia dan berapa jumlah tanggung jawab atau beban kerja yang tepat dilimpahkan kepada seorang petugas.

RSUD Sanjiwani Gianyar merupakan salah satu rumah sakit umum daerah milik pemerintah yang ada di Kabupaten Gianyar yang merupakan pusat rujukan Bali Timur. Adapun fasilitas dan sarana pelayanan yang ada di RSUD Sanjiwani Gianyar meliputi rawat jalan yang terdiri dari 19 jenis Poliklinik Spesialis dengan jumlah karyawan 51 yang meliputi karyawan Paramedis Keperawatan.

Berdasarkan permasalahan yang diteliti, desain penelitian yang digunakan pada penelitian ini merupakan penelitian kuantitatif. Penelitian kuantitatif adalah penelitian yang dilakukan dengan mengumpulkan data yang berupa angka. Populasi dalam penelitian ini adalah seluruh karyawan paramedis keperawatan di Poliklinik RSUD Sanjiwani Gianyar sebanyak 51 orang. Metode penentuan sampel adalah metode sensus/jenuh. Dengan demikian
Dalam menyelesaikan suatu pekerjaan para karyawan harus memiliki semangat kerja untuk menyelesaikan pekerjaan lebih baik dan cepat. Dalam observasi yang dilakukan di RSUD Sanjiwani, salah satu faktor penyebab turunnya semangat kerja adalah adanya keterlambatan dalam pemberian insentif jasa pelayanan, sedangkan karyawan sangat berperan penting dalam meningkatkan atau mencapai tujuan perusahaan, maka pemberian insentif jasa pelayanan yang memadai dan tepat waktu kepada karyawan perlu mendapatkan perhatian khusus sehingga mereka dapat melaksanakan tugasnya dan dapat mengembangkan kemampuan mereka semaksimal mungkin. Insentif jasa pelayanan sangat diperlukan sebagai reward untuk memacu semangat para karyawan agar selalu berada pada tingkat tertinggi (optimal) sesuai kemampuan masing-masing.

Tujuan dalam penelitian ini untuk mengetahui pengaruh insentif jasa pelayanan, kepemimpinan dan beban kerja secara parsial dan simultan terhadap semangat kerja karyawan di RSUD Sanjiwani Gianyar.

\section{METODE PENELITIAN}

jumlah sampel dalam penelitian ini adalah 51 orang.

Metode pengumpulan data menggunakan teknik observasi, wawancara, dokumentasi, dan kuesioner. Pengukuran yang digunakan dalam penelitian adalah pengukuran dengan skala linkert, dengan perhitungan skor yaitu: skor SS (Sangat Setuju)=5, skor S (Setuju)=4, skor KS (Kurang Setuju $)=3$, skor TS $($ Tidak Setuju $)=2$, skor STS (Sangat Tidak Setuju) $=1$. Pengujian data menggunakan uji 
validitas, uji realiabilitas. Teknik analisis data menggunakan pendetakan kuantitatif yaitu asumsi klasik, analisis

Seluruh variabel pada uji validitas memiliki nilai koefisien korelasi berada di atas 0,3 dengan demikian semua instrumen tersebut adalah valid, sehingga layak dijadikan instrumen penelitian.

Seluruh variabel pada uji reliabilitas memiliki nilai koefisien Alpha Cronbach berada di atas 0,6 dengan demikian regresi linier berganda, uji $\mathrm{t}$ (secara parsial), uji F (secara simultan).

\section{HASIL DAN PEMBAHASAN Uji Validitas dan Reliabilitas Instumen Penelitian}

semua instrumen tersebut adalah reliabel, sehingga layak dijadikan instrumen penelitian.

Uji Asumsi Klasik

Uji asumsi klasik digunakan untuk mengetahui kelayakan penggunaan model regresi. Hasil uji normalitas dapat dilihat pada Tabel 1

Tabel 1

Hasil Uji Normalitas

\begin{tabular}{lr}
\multicolumn{2}{c}{ One-Sampel Kolmogorov-Smirnov Test } \\
\hline $\mathrm{N}$ & Unstandardized Residual \\
\hline Kolmogorov-Smirnov Z & 51 \\
Asymp. Sig. (2-tailed) & .970 \\
Sumber: Pengolahan Data Penelitian Pada Lampiran
\end{tabular}

Berdasarkan Tabel 1, dapat diketahui hasil uji normalitas memiliki tingkat signifikansi sebesar 0,303 > 0,05 sehingga dapat dikatakan bahwa model regresi memenuhi asumsi normalitas.

Hasil Uji Heteroskedastisitas pada penelitian ini dapat dilihat pada Tabel 2

Tabel 2

Hasil Uji Heteroskedastisitas

Coefficients $^{a}$

\begin{tabular}{lrr}
\hline \multicolumn{1}{c}{ Model } & \multicolumn{2}{c}{ Sig. } \\
\hline (Constant) & 1.759 & .085 \\
X1 & .377 & .708 \\
X2 & -1.021 & .313 \\
X3 & -1.752 & .086 \\
\hline a. Dependent Variable: ABS & \\
Sumber: Pengolahan Data Penelitian Pada Lampiran
\end{tabular}

Berdasarkan Tabel 2, dapat diketahui bahwa semua variabel memiliki tingkat signifikansi lebih besar dari 0,05. Hal ini berarti pada model regresi tidak terdapat gejala heteroskedastisitas.

Hasil Uji Multikolonearitas pada penelitian ini dapat dilihat pada Tabel 3. 
Tabel 3

Hasil Uji Multikolonearitas

\begin{tabular}{llcr}
\multicolumn{4}{c}{ Coefficients $^{\mathbf{a}}$} \\
\cline { 3 - 4 } Model & \multicolumn{2}{c}{ Collinearity Statistics $^{\text {Tolerance }}$} & VIF \\
\cline { 3 - 4 } & (Constant) & & \\
& X1 & .945 & 1.058 \\
& X2 & .712 & 1.405 \\
X3 & .743 & 1.346 \\
\hline a. Dependent Variable: Y & & \\
Sumber: Pengolahan Data Penelitian Pada Lampiran
\end{tabular}

Berdasarkan Tabel 3, dapat dilihat bahwa seluruh variabel bebas memiliki nilai VIF tidak lebih dari 10 dan mempunyai angka tolerance tidak kurang dari 0,1. Hal ini berarti bahwa tidak terdapat gejala multikolinearitas dari model regresi yang digunakan.

\section{Analisis Regresi Linier Berganda}

Hasil analisis regresi linier berganda dapat dilihat pada Tabel 4 .

Tabel 4

Hasil Uji Regresi Linier Berganda

\begin{tabular}{|c|c|c|c|}
\hline \multicolumn{4}{|c|}{ Coefficients $^{a}$} \\
\hline & & \multicolumn{2}{|c|}{ Unstandardized Coefficients } \\
\hline \multicolumn{2}{|c|}{ Model } & $\mathrm{B}$ & Std. Error \\
\hline \multirow[t]{4}{*}{1} & (Constant) & 3.631 & 3.424 \\
\hline & $\mathrm{X} 1$ & .218 & .103 \\
\hline & $\mathrm{X} 2$ & .759 & .072 \\
\hline & X3 & -.134 & .066 \\
\hline \multicolumn{4}{|c|}{ a. Dependent Variable: Y } \\
\hline
\end{tabular}

Berdasarkan hasil analisis dapat diketahui bahwa nilai konstanta $\alpha=$ 3,631 dan nilai koefisien regresi $\beta 1=$ $0,218, \beta 2=0,759$ dan $\beta 3=-0,134$ sehingga diperoleh persamaan regresi linier berganda sebagai berikut :

$$
\begin{aligned}
Y= & 3,631+0,218 X_{1}+0,759 X_{2}- \\
& 0,134 X_{3}
\end{aligned}
$$

Sehingga memberikan informasi sebagai berikut: $\alpha=3,631$, artinya nilai tersebut menunjukkan apabila nilai insentif jasa pelayanan $\left(\mathrm{X}_{1}\right)$, kepemimpinan $\left(\mathrm{X}_{2}\right)$ dan beban kerja $\left(\mathrm{X}_{3}\right)$ sama dengan nol, maka nilai semangat kerja adalah 3,631, nilai $\beta 1=0,218$, artinya apabila insentif jasa pelayanan dinaikkan satu satuan maka semangat kerja akan meningkat sebesar 0,218 dengan asumsi nilai kepemimpinan dan beban kerja konstan, ini berarti jika insentif jasa pelayanan ditingkatkan maka semangat kerja karyawan akan meningkat pula. Nilai $\beta 2=0,759$, artinya apabila kepemimpinan dinaikkan satu satuan maka semangat kerja akan meningkat sebesar 0,759 dengan asumsi nilai insentif jasa pelayanan konstan dan 
beban kerja, ini berarti jika kepemimpinan ditingkatkan maka semangat kerja akan meningkat pula. Nilai $\beta 3=-0,134$, artinya apabila beban kerja dinaikkan satu satuan maka semangat kerja akan menurun sebesar 0,134 dengan asumsi nilai insentif jasa pelayanan dan kepemimpinan konstan, ini berarti jika beban kerja ditingkatkan maka semangat kerja akan menurun.

\section{Analisis Determinasi}

Hasil analisis determinasi dapat dilihat pada Tabel 5.

Tabel 5

Hasil Analisis Determinasi

\begin{tabular}{lrr}
\hline \multicolumn{3}{c}{ Model Summary } \\
\hline \multicolumn{1}{c}{$\mathrm{R}$} & \multicolumn{2}{c}{ R Square } \\
\hline \multicolumn{1}{c}{1} & $.871^{\mathrm{a}}$ & .759 \\
\hline a. Predictors: (Constant), X2, X1 & \\
\hline Sumber: Pengolahan Data Penelitian Pada Lampiran
\end{tabular}

Berdasarkan data pada Tabel 5 , ini berarti kontribusi insentif jasa pelayanan, kepemimpinan, dan beban kerja terhadap semangat kerja karyawan pada RSUD Sanjiwani Gianyar sebesar $75,9 \%$ sedangkan sisanya sebesar $24,1 \%$ merupakan kontribusi dari variabel lain yang tidak diteliti dalam penelitian ini.

\section{Hasil Analisis Uji t (Uji Parsial)}

Hasil uji hipotesis menggunakan uji statistik $\mathrm{t}$ (t-test) dapat dilihat pada Tabel 6 , berikut.

Tabel 6

Hasil Analisis Uji T (Uji Parsial)

\begin{tabular}{llrr}
\hline \multicolumn{4}{c}{ Coefficients $^{\mathbf{a}}$} \\
\hline Model & \multicolumn{1}{c}{} \\
\hline 1 & (Constant) & 1.061 & .294 \\
& X1 & 2.116 & .040 \\
X2 & 10.525 & .000 \\
& X3 & -2.020 & .049 \\
\hline a. Dependent Variable: $Y$ & \\
\hline \multicolumn{4}{l}{ Sumber: Pengolahan Data Penelitian Pada Lampiran }
\end{tabular}

Berdasarkan Tabel 6 diperoleh data dengan penjelasan sebagai berikut:

Berdasarkan hasil pengujian, ternyata dengan pada tingkat keyakinan 95\%, kesalahan 5\% dan derajat bebas 47 diperoleh nilai t-hitung 2,116 dan nilai ttabel $=2,012$ sehingga bila dibandingkan maka nilai t-hitung lebih besar dari nilai t-tabel dan t-hitung berada pada daerah penolakan Ho. Oleh karena itu, Ho ditolak dan Ha diterima. Ini berarti bahwa insentif jasa pelayanan berpengaruh positif dan signifikan terhadap semangat kerja, dengan kata 
lain hipotesis yang menyatakan bahwa insentif jasa pelayanan berpengaruh positif dan signifikan terhadap semangat kerja karyawan pada RSUD Sanjiwani Gianyar dapat diterima.

Berdasarkan hasil pengujian, ternyata dengan pada tingkat keyakinan 95\%, kesalahan 5\% dan derajat bebas 47 diperoleh nilai t-hitung 10,525 dan nilai $\mathrm{t}$-tabel $=2,012$ sehingga bila dibandingkan maka nilai t-hitung lebih besar dari nilai t-tabel dan t-hitung berada pada daerah penolakan Ho. Oleh karena itu, Ho ditolak dan Ha diterima. Ini berarti bahwa kepemimpinan berpengaruh positif dan signifikan terhadap semangat kerja, dengan kata lain hipotesis yang menyatakan bahwa kepemimpinan berpengaruh positif dan signifikan terhadap semangat kerja karyawan pada RSUD Sanjiwani Gianyar dapat diterima.
Berdasarkan hasil pengujian, ternyata dengan pada tingkat keyakinan $95 \%$, kesalahan 5\% dan derajat bebas 47 diperoleh nilai t-hitung -2,020 dan nilai negatif $\mathrm{t}$-tabel $=2,012$ sehingga bila dibandingkan, maka nilai t-hitung lebih kecil dari nilai t-tabel dan t-hitung berada pada daerah penerimaan Ho. Oleh karena itu, Ho ditolak dan $\mathrm{Ha}$ diterima. Ini berarti bahwa beban kerja berpengaruh negatif dan signifikan terhadap semangat kerja, dengan kata lain hipotesis yang menyatakan bahwa beban kerja berpengaruh negatif dan signifikan terhadap semangat kerja karyawan pada RSUD Sanjiwani Gianyar diterima.

\section{Hasil Analisis Uji F (Uji Simultan)}

Hasil uji hipotesis menggunakan uji statistik t (t-test) dapat dilihat pada Tabel 7 , berikut.

Tabel 7

Hasil Analisis Uji F (Uji Simultan)

\begin{tabular}{|c|c|c|c|}
\hline \multicolumn{4}{|c|}{ ANOVA $^{b}$} \\
\hline Model & & $\mathrm{F}$ & Sig. \\
\hline \multirow[t]{3}{*}{1} & Regression & 49.290 & $.000^{\mathrm{a}}$ \\
\hline & Residual & & \\
\hline & Total & & \\
\hline \multicolumn{4}{|c|}{ a. Predictors: (Constant), X2, X1 } \\
\hline \multicolumn{4}{|c|}{ b. Dependent Variable: $Y$} \\
\hline
\end{tabular}

Berdasarkan Tabel 7 diperoleh data dengan penjelasan sebagai berikut: Berdasarkan hasil pengujian, maka dapat disimpulkan bahwa pada tingkat keyakinan 95\%, kesalahan 5\%, derajat bebas pembilang 3 dan derajat bebas penyebut 47, diperoleh nilai F-hitung = 49,290 dan nilai F-tabel $=2,80$ sehingga bila dibandingkan maka nilai F-hitung lebih besar dari F-tabel, dan F-hitung berada pada daerah penolakan Ho. Oleh karena itu, Ho ditolak dan Ha diterima. Ini berarti bahwa insentif jasa pelayanan, kepemimpinan, dan beban kerja berpengaruh positif dan signifikan, dengan kata lain hipotesis yang menyatakan bahwa insentif jasa pelayanan, kepemimpinan, dan beban kerja berpengaruh positif dan signifikan terhadap semangat kerja karyawan pada RSUD Sanjiwani Gianyar dapat diterima. 


\section{PENUTUP \\ KESIMPULAN}

Hasil analisis regresi linier berganda diperoleh persamaan regresi $\mathrm{Y}=3,631+0,218 \mathrm{X}_{1}+0,759 \mathrm{X}_{2}-$ $0,134 X_{3}$. Dari persamaan tersebut dijelaskan bahwa ada pengaruh yang positif dan signifikan dari insentif jasa pelayanan, kepemimpinan, dan beban kerja terhadap semangat kerja karyawan RSUD Sanjiwani Gianyar. Berdasarkan uji statistik diperoleh nilai $\mathrm{F}$ hitung sebesar 49,290> F tabel sebesar 2,80 dengan signifikansi $0,000<0,05$. Ini berarti bahwa insentif jasa pelayanan, kepemimpinan, dan beban kerja secara simultan memang benar dan nyata berpengaruh signifikan terhadap semangat kerja karyawan, jadi tidak karena kebetulan. Hasil analisis determinasi didapat $75,9 \%$ sedangkan sisanya sebesar $24,1 \%$ dipengaruhi oleh faktor lain yang tidak diteliti dalam penelitian ini. Secara parsial insentif jasa pelayanan berpengaruh positif dan signifikan terhadap semangat kerja dengan koefisien regresi sebesar 0,218, nilai thitung sebesar 2,116 $>t_{\text {tabel }}$ sebesar 2,012 serta nilai signifikan uji t sebesar $0,040<0,05, \quad$ sehingga hipotesis diterima. Secara parsial kepemimpinan berpengaruh positif dan signifikan terhadap semangat kerja dengan koefisien regresi sebesar 0,759, nilai $t_{\text {hitung }}$ sebesar 10,525 $>t_{\text {tabel }}$ sebesar 2,012 serta nilai signifikan uji t sebesar $0,000<$ 0,05 , sehingga hipotesis diterima. Secara parsial beban kerja berpengaruh negatif dan signifikan terhadap semangat kerja dengan koefisien regresi sebesar $-0,134$, nilai thitung sebesar $-2,020>t_{\text {tabel }}$ sebesar 2,012 serta nilai signifikan uji t sebesar $0,049<0,05$, sehingga hipotesis ditolak.

\section{SARAN-SARAN}

Berdasarkan uraian kesimpulan tersebut di atas, maka saran yang sekiranya dapat dipertimbangkan berkaitan dengan pengaruh insentif jasa pelayanan, kepemimpinan, dan beban kerja terhadap semangat kerja karyawan adalah sebagai berikut:

Disarankan kepada RSUD Sanjiwani Gianyar agar dalam pemberian insentif melihat proporsi karyawan dalam bekerja, dan kinerja yang dihasilkan sehingga karyawan akan lebih semangat dalam bekerja untuk mendapatkan insentif yang lebih tinggi. Kepada pimpinan RSUD Sanjiwani Gianyar agar dapat menambah meningkatkan fasilitas yang diberikan kepada karyawan serta memberikan bonus untuk karyawan dengan tingkat kinerja yang tinggi sehingga karyawan semakin semangat dalam bekerja.

Kepada RSUD Sanjiwani Gianyar untuk memberikan pendidikan dan pelatihan yang lebih baik kepada karyawan sehingga karyawan memiliki pengalaman dan pengetahuan yang lebih baik dalam menyelesaikan tugas-tugas yang diberikan. RSUD Sanjiwani Gianyar dalam usaha meningkatkan semangat kerja untuk meningkatkan insentif yang diberikan, meningkatnya insentif diharapkan dapat meningkatkan pula semangat karyawan dalam bekerja dan memberikan hasil yang lebih baik kepada RSUD Sanjiwani Gianyar. 
DAFTAR PUSTAKA

Adil Kurnia. 2010. Definisi Analisis Beban Kerja. Jakarta: Ghalia Indonesia

Ahmad, Komaruddin. 1996. DasarDasar Manajemen Investasi. Edisi Revisi Jakarta: Rineka Cipta.

Alex S. Nitisemito. 2010. Manajemen personalia Manajemen Sumber Daya Manusia. Edisi Ketiga. Jakarta: Ghalia Indonesia

Alex S. Nitisemito. 2002. Wawasan Sumber Daya Manusia. Jakarta: Pustaka Utama Grafiti.

Asnawi, Sahlan. 1999. Aplikasi Psikologi dalam Manajemen Sumber Daya Manusia Perusahaan. Jakarta: Pusgrafin

Bacal, Robert. 2005. Performance Management. Jakarta: Gramedia

Budi, Setiyawan.,Waridin. 2006. Pengaruh Disiplin Kerja Karyawan dan Budaya Organisasi Terhadap Kinerja di Divisi Radiologi RSUP Dokter Kariadi, Semarang: JRBI. Vol 2. No 2. Hal: 181-198

Davis, Keith., John W. Newstrom. 1985.Perilaku Dalam Organisasi. Jakarta: Erlangga.

Gorda,I Gusti Ngurah. 2004. Manajemen Sumber Daya Manusia.Edisi Revisi. Denpasar: Astabrata Bali bekerjasama dengan STIE Satya Dharma Singaraja.
Ghozali, Imam. 2013. Aplikasi Analisis Multivariate dengan Program IBM SPSS 21 Update PLS Regresi.Semarang:Badan

Penerbit

Universitas

Diponegoro.

Hatch, E., Farhady, H. 1981 Research Design and Statistics for Applied Linguistics, Teheran: Rahnama Publications.

Husein, Umar. 2011. Metode Penelitian Untuk Skripsi dan Tesis Bisnis Edisi 11. Jakarta: PT Raja Grafindo Persada.

S.P,Hasibuan, Malayu. 2013. Manajemen Sumber Daya Manusia. Jakarta: PT Bumi Aksara.

Kartini Kartono. 2011.Pemimpin dan Kepemimpinan, Jakarta: PT. Rajawaligrafindo Persada.

Noor, Juliansyah. 2011. Metodologi Penelitian, Prenada Media Group, Jakarta

Permenkes-21-Tahun-2016Penggunaan-Dana-Kapitasi$J K N$-untuk-FKTP-pdf. Retrieved January 14,2019, from djsn.go.id

Putra, A. S. 2012. Analisis Pengaruh Beban Kerja Terhadap Kinerja Karyawan Divisi Marketing dan Kredit PT. WOM Finance Cabang Depok.Skripsi.Institut Pertanian Bogor.

Rivai, Veithzal., Deddy Mulyadi. 2012. Kepemimpinan dan Perilaku Organisasi Edisi Ketiga. Jakarta: PT. Rajagrafindo Persada. 
Siagian, S. P. 2002. Manajemen Sumber Daya Manusia. Jakarta: Bumi Aksara.

Sugiyono. 2009. Metode Penelitian Kuantitatif, Kualitatif dan $R \& D$.Bandung: Alfabeta.

Sugiyono. 2010. Metode Penelitian Pendidikan Pendekatan Kuantitatif, kualitatif, dan $R \& D$. Bandung: Alfabeta.

Sugiyono. 2016. Metode Penelitian Kuantitatif Kualitataif dan Kombinasi Mixed Methods. Bandung: Alfabeta.

Tarwaka. 2011. Ergonomi Industri, Dasar-Dasar Pengetahuan Ergonomi dan Aplikasi Di Tempat Kerja. Surakarta: Harapan Press.

Thoha,Miftah. 2011. Perilaku Organisasi, Konsep Dasar dan Aplikasinya. Rajawali Pers. Jakarta.

Universitas Ngurah Rai Denpasar. 2008. Buku Panduan Penyusuanan Proposal dan Skripsi Tahun 2018. Denpasar. Fakultas Ekonomi. 